\title{
Euphoria, CTCAE 5.0
}

National Cancer Institute

\section{Source}

National Cancer Institute. Euphoria, CT CAE 5.0. NCI Thesaurus. Code C146748.

A disorder characterized by an exaggerated feeling of well-being which is

disproportionate to events and stimuli. 